light of Japan" had, as was customary at this season of the year when the weather is very cold, stormy, and clear, been observed by fishermen in the Shimbara Gulf and Japanese waters. The article went on to say that these lights were referred to in native school-books, and attributed to electrical phenomena. On mentioning the matter, however, to the leading Europeans in Yokohama and Tokio, they appeared to have no knowledge of the matter.

Captain Castle, of H.M.S. Leander, informed me that, not long ago, the officers of his ship saw lights in the same locality which they thought at first were caused by a ship on fire. The course of the vessel was altered at once with a view of rendering assistance, tut finding that the lights increased their altitude as he approached, he attributed them to some volcanic disturbance, and being pressed for time, resumed his course.

The background of high land seen on the first night dispels all idea of these extraordinary lights being due to a distant volcano. The uniformity of the bearing renders the theory of their being fires on the shore most improbable. I am inclined to the belief that they were something in the nature of St. Elmo's fires. It is probable that there are travellers among the readers of your interesting journal who have seen or heard of this phenomenon, and will be able to describe its origin and the atmospheric conditions necessary for its appearance.

H.M.S. Caroline, Hongkong, April ro. Chas. J. NORCOCK.

\section{The Greatest Rainfall in Twenty-four Hours.}

In Nature, May 4, Mr. Clement Wragge, of Brisbane, confidently asserts that Queensland has beaten the world's record in the extraordinary amount recorded on February 3 , viz., 35.7 inches. I am sorry to have to take away such an unenviable palm from Queensland, by recalling a fact well known to every Indian meteorologist that the highest record extant belongs to Chirapunji, in the Khasia hills, where on June $14,1876,40.8$ inches were recorded in the twenty-four hours. Not only so, but on the r 2th 30 inches fell, and in the four days, from the 12 th to the $15^{\text {th }}$ inclusive, as much as 102 inches. Of course the effects were not so disastrous in this case, as indeed such a state of things is little removed from the normal at Chira in the early part of June, but I have a very clear recol lection of it as I was at Chirapunji on the 12 th and 13 th, and not far from it on the memorable 14th.

The conditions which have occurred in Queensland and the North Island of New Zealand during the last six months have been a remarkable example of persistent abnormals, and though the total number of rational causes may still be wanting to explain everything, one or two were evidently in operation wher I was there from October to January, and I am confident that from the empirical law of persistency, coupled with a few rational inferences, a forecast of impending floods could have been made and can be made for the future, much in the same way as the general character of the monsoon can be foretold in India.

May 13.

\section{E. Douglas Archibald.}

\section{A Dust-whirl or (?) Tornado.}

IN NATURE (vol. xl. p. I74) you kindly allowed me to describe a dust-whirl seen to originate on a heated dust-covered highway. The phenomenon has just been repeated under much similar circumstances, only in this instance the column of dust after oscillating to and fro on the highway for about half a minute, moved rapidly away in a curvilinear path in a northerly direc. tion, the lower end of the whirl catching up loose material in its track where it touched the ground, which it did at intervals of from ten to fifteen yards, carrying the strawy litter from a strawberry bed upwards of 50 yards in the air. It appeared to dissipate into the upper air when crossing a meadow some 300 yards from its place of origin. The characteristic "swish" of the rushing air was very marked, and the four motions common to all tornadoes (see Lieut. Finley's "Character of Six Hundred Tornadoes"), viz. whirling from right to left, progressive motion to the north, a curvilinear track, and the dipping up and down, were all distinctly traced. The question therefore, naturally arises-Can these dust-whirls be tornadoes in miniature?

Conditions at the time of the occurrence :-Date, Thursday, May II, I893: time, II a.m. Corrected barometer, 30.327 (falling slightly). Dry bulb, $66^{\circ} .5$; wet, $51^{\circ} .8=$ rel, hum. 38 per cent. Wind, south; force, 1 . Some upper cirrus radiating from north-east, and drifting slowly from north-west, showing top and bottom arcs of halo at ro a.m. Black bulb in vacuo $128^{\circ} .2$; weather very warm and dry.

Driffield, May I 1 .

J. LOVEL.

What becomes of the Aphis in the Winter?

I HAVE spent many weeks this spring closely observing the budding trees, with the object of discovering in what condition of life the aphis spends the winter; as the result of my observations, which were made under the microscope, I believe that the aphidæ during the autumn (or as many of them as have reached the state of reproduction) attach themselves to the stem of the tree, with their young inside them, in much the same way as the female members of the closely-allied family coccidre do. In course of time the mother-aphis becomes simply a dried skin serving as a pr stection to the young. When the warm days of spring come these are developed and easily make their way through the skin and crawl on to the young leaves, there to begin their work of sucking and reproduction.

\section{T. A. Sharpe,}

\section{Soot-figures on Ceilings.}

MAY I suggest a distinct, if not an alternative cause for Prof. E. B. Poulton's soot figures in NATURE, April 27th? The ceiling plaster is very porous, except where it is in contact with the joists, etc. At such points very little deposit occurs compared with the spaces where the hot air is vigorously diffusing through into the cold space above. I suggest this because I am very familiar with a large ceiling where the rafters are thus picked out in light shades. Even the laths are picked out, but less distinctly. The main bolts likewise show dark, as in Prof. Poulton's sketch, as if there were an air-space by them. There is no perceptible difference in the figures near the central chandelier from those in the corners remotest from heating causes. The bombarding pattern is often very well shown where super-heated water pipes run along a white-washed wall. The effect of every little break, even a nail in the wall, is most striking.

J. EDMUND ClaRK.

\section{A Difficulty in Weismannism Resolved.}

Is my letter of the Ist inst. an omission of parentheses and quotation marks, which I omitted to note on the proof, alters the sense of the paragraph with quotations from the "Germ Plasm," pp. 434-5. It should be as follows:- " The note runs thus: 'Compare Marcus Hartog, NATURE, vol. xliv. p. 102,' (the reference omits my letter of Oct. $31,189 \mathrm{I}$ ). 'The deductions made by this author are logically correct but are no longer justifiable, since I myself have gained further insight into the problems concerned.' "'The absence of the inverted commas disguises this recognition by Weismann of the validity of my objections, and of the consequent change in his own views.

Cork, May 15.

MaRCUS HARTOG.

\section{NOTES.}

THE Hon. Ralph Abercromby has given to the Royal Society of New South Wales the sum of $£ \mathrm{roo}$, which is to be offered as prizes with the object of bringing about exhaustive studies of certain features of Australian weather. So far only one feature has been selected, and a prize of $£ 25$ is now offered for an exhaustive study of the well-known "Southerly Burster." It is understood that no essay which does not deal fully with the following points will be considered:-(I) The motions of the various strata of clouds for some hours preceding, at the time of, and following the "burster;" (2) the weather conditions which lead up to and follow the "burster," with weather charts of Australia for the day of occurrence and the following day ; (3) the general conditions which modify the character of the "burster;" (4) The area of the "burster" and its track; (5) barograph traces showing the changes of pressure during the "burster;" (6) the direction and character of wind preceding it ; $(7)$ the relation of "bursters" to rainfall. The essay must not exceed 50 pages of foolscap, and must be sent in not later than March 31, I894. It must embody studies of several "bursters," and must be chiefly the result of original research of the author, but authors

No. I 230 , voL. 48 ] 